\title{
Design of Seashore Wastage Cleaning Machine using IOT
}

\author{
R. Puviarasi, M. Mohammedariefrahuman, S.R.Boselin Prabhu
}

\begin{abstract}
Sea cleaning is troublesome now a days so we improved our innovation to clean the sea or any water bodies naturally utilizing keen innovation with the assistance of hub $M C U$ and IOT stage. The engine of watercraft i.e., the course of pontoon and development of vessel is controlled utilizing cell phone which has an utilization of IOT which can be interfaced with the microcontroller. In the wake of interfacing we can control the pontoon with joystick gadget that is accessible in Bylnk application. Later with the assistance of transport all the refuse are gathered consequently and kept to the junk that is mounted on the watercraft. After the case is filled then the transport will stop and we can move the pontoon to the keeping region. What's more, this entire procedure is done remotely with the assistance of IOT innovation.
\end{abstract}

Keywords-IoT, motor power supply, bylnk, mobile phone

\section{INTRODUCTION}

Plastics are an engineered natural polymer that has been around just for a little more than a century. Its qualities of delicacy, toughness, quality, generally minimal effort of creation, and adaptability of utilization have added to its entering all parts of regular daily existence. Then again, similar qualities that helped increment plastic creation together with reckless administration of its transfer are additionally in charge of making the material a genuine danger for the earth. I Non-managed landfills sited close-by waterways and in seaside regions combined with unlawful dumping, littering and sea based dumping can possibly bring plastic squanders into the seas, as confirmed by a few creators:. "In the US, flood components, incorporated with sewage framework to redirect the wastewater and storm water to abstain from over-burdening the sewer framework, are one of the real land-based wellsprings of plastics .overused and ineffectively overseen landfill and exchange stations can build marine garbage. Rubbish that is inappropriately secured amid transport or affidavit into landfills can be conveyed by wind into the marine condition or into other amphibian frameworks that vehicle the waste to the marine condition." temperature, barometric weight, wind, sea shading, and saltiness and have a transmitter to send the information to satellites. The drogue is suspended at a profundity of 15 meters underneath the ocean surface. While the float measure shifts, makers attempt to keep a drag zone proportion - characterized as the proportion of the drag territory of the drogue over the drag of the non-drogue component - of 40, which permits minimization of the

Revised Manuscript Received on August 19, 2019.

Dr.R.Puviarasi,Department of ECE, Saveetha school of Engineering, Saveetha Institute of Medical and Technical Sciences, Chennai T.N, India.

M.Mohammedariefrahuman,Department of ECE, Saveetha school of Engineering, Saveetha Institute of Medical and Technical Sciences, Chennai T.N, India.

Dr.S.R.BoselinPrabhu, Department of ECE, Surya Engineering College, Mettukadai, T.N, India. downwind slip - the even movement of a wanderer because of wind flows that contrasts from the horizontal movement of flows arrived at the midpoint of over the drogue profundity Despite the fact that the wanderers may not appear to be illustrative of the plastic refuse, they are incredibly valuable and precise in foreseeing how plastic squanders total at specific zones in the seas.

The Garbage Patch The waste fix is a grouping of marine flotsam and jetsam in the sea. It comprises for the most part of plastic articles with a surmised convergence of around 46,000 pieces for every square mile, as indicated by the United Nations Environmental Program 2006 evaluations (UNEP). There are five fundamental waste patches. The biggest is alluded to as the Great Pacific Garbage Patch and comprises of the Eastern Garbage Patch and the Western Garbage Patch. The wellsprings of plastic flotsam and jetsam can be land-based (assessed at $80 \%$ ) or sea based and they identify with four fundamental classifications: sewage, the travel industry, angling, and waste from boats and vessels. The first incorporates garbage that originates from tempest water releases, consolidate sewer floods, and strong waste transfer and landfills; it is conveyed to the ocean in streams, streams, and, shockingly, underground conduits. Garbage disposed of in the lanes, walkways, drains and somewhere else is conveyed by water stream or wind and in the long run winds up in the sea. This is additionally valid with trash thoughtlessly released in the toilets or sinks at home. Moreover, mechanical items can end up marine flotsam and jetsam if not legitimately discarded. Vacationer littering is one of the significant reasons for shoreline contamination that in the end is changed to marine trash. At long last all vessels and dispatches and seaward mechanical stages are potential wellsprings of sea contamination, as they can produce waste, either purposefully or incidentally. It ought to be noticed that there are four principle measurements to the issue of the plastic refuse fix: a) Plastic is exceptionally scattered as it buoys and moves in the huge sea; b) there is a ceaseless collection of waste, as plastic does not biodegrade; c) it is a worldwide as opposed to a national issue; and d) it is hard to demonstrate causation between measure of plastic squanders in the seas and consequences for the biological systems in the sea.

\section{WORKING PRINCIPLE}

Proof (RFID), following the accumulation vehicle, Dustbin observing and other rising detecting advances 


\section{Block diagram}

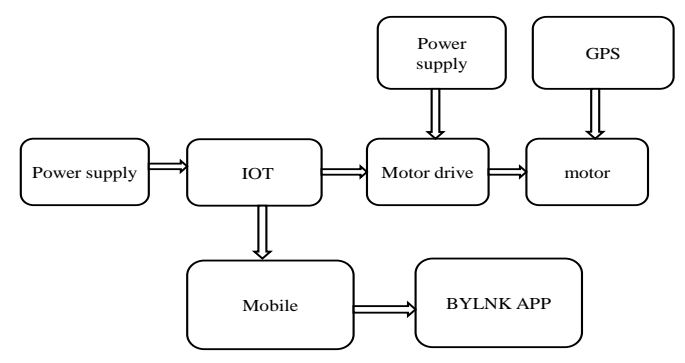

Fig1.Block diagram of seashore wastage cleaning machine using IOT

Amid the execution of my task we have used IOT as the working in the field of arranged radio-recurrence recognizable. The motivation behind controller is to keep up yield voltage steady. One of controllers yield is legitimately given to the small scale controller and the controller yield is given to the microcontroller through Wi-Fi modem.

\section{EXISTING SYSTEM}

The correspondence conventions will be intended for the Internet of Things stage where all articles or things are consolidated to dissect area. The rectifier yield is given to the both of the controllers IOT is new frameworks might be conveyed by means of the web, this does not really imply that the web all things considered will change or that there will be another "structure" of web just proposed to be utilized for data trade between these new specialized apparatuses. For example, Cisco predicts the IoT and the quantity of gadgets associated with the Internet surpassing the quantity of individuals populating the whole planet. What's more, that is not simply advanced mobile phones and tablets. Its sensors empowering a keen matrix, more astute transportation streams, following the soundness of steers, and gadgets checking including propelled correspondence conventions that associate brilliant gadgets in condition. An IoT application often includes a gadget or a shrewd article transmitting data in regards to its state, setting, or tactile estimations to different customers or gadgets. There is another convention Message Queue Telemetry Transport (MQTT) that is created by specialists at IBM. It is planned as a lightweight EM distribute/buy in informing transport availability convention. It has likewise been coordinated with the IBM web sphere application server. The MQTT convention determination portrays the convention to be in a perfect world appropriate for asset compelled conditions where the system keeps running on implanted gadgets with constrained processor or memory assets and is costly, has low transfer speed, or is questionable. While MQTT depends on the TCP/IP stack, MQTT-S is an augmentation for non-TCP/IP stacks, remembering low-end sensor gadgets.

\section{PROPOSED SYSTEM}

The proposed Internet of Things structure will deal with institutionalization, interoperability perspectives with the assistance of which different area explicit applications can be fabricated. The proposed Internet of Things This is an autonomous layer that interoperates with the IoT structure to give space explicit and application situated administrations. IoT Framework involves the Utility Layer This layer contains utilities that can be utilized by different applications in application administration layer. The conceivable utilities for applications like route, following, area administrations.IoT Service Layer - This layer gives different administrations to interoperability among substances in focused IoT condition. This incorporates different administrations like gadget correspondence administration, gadget the executives administration, middle person administration, security administration, area administration, information administration and outside interface administration and so forth..IoT condition speaks to the system of the physical substances or things in the Internet of Things.

\section{TESTS AND RESULTS}

Versatility of gadgets is considered as one of critical parts of Internet of Things where gadgets get associated with one another. Versatility includes two procedures. The main procedure in wandering that includes moving starting with one system then onto the next and different procedure is handover that will include changing purpose of connection when information streams. Along these lines, it is fundamental to diminish the handoff delay amid handover that is acquainted at various layers with give better proficiency to end clients. Portability can likewise be classified as miniaturized scale versatility that includes versatility inside the system and large scale portability that includes versatility among system spaces where IP address changes. [1-4] There are different reasons for portability that incorporates physical developments, radio channels, organizes execution, rest calendars and hub disappointment. End clients can acquire their very own gadgets IoT condition as a piece of Bring Your Own Device (BYOD) upheaval and consequently gadget versatility is one of the vital perspectives that should be considered in Internet of Things. The quantity of IoT gadgets is incredibly vast as they provide food different applications and administrations under IoT and henceforth revelation of gadgets that includes the naming and tending to plans is pivotal and troublesome The IoT framework ought to be adaptable in supporting more than one naming plans. It should bolster recognizable proof of gadgets/things of IoT by their names, impermanent ID, pseudo-name, area or mix thereof. It will be conceivable to re-utilize these names and IDs for specific classes of gadgets or in a domain where assets are obliged. The naming framework ought to be adaptable and ought to permit attachment and play sort of condition. Tending to in IoT ought to likewise bolster revelation of gadgets and abilities. This ought to be incorporated into the naming and limitation instrument. Variables managing gadget trade, disappointment, area change because of portability or administration relocation ought to likewise be considered in the tending to system. Accentuation ought to be given for the utilization of one of a kind IDs to the gadgets; with the end goal that ID based security can be conveyed in future.

Published By:

Blue Eyes Intelligence Engineering

\& Sciences Publication

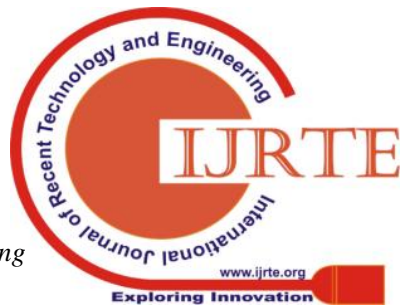


VI. RESULT ANALYSIS

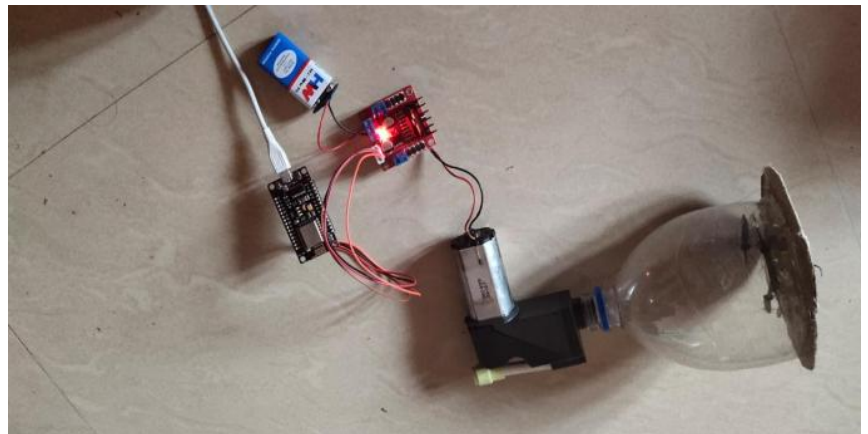

Fig.2 .Experimental setup of seashore wastage cleaning machine using IOT

\section{CONCLUSION}

The observing and controlling of machines in industry has turned into a noteworthy issue. By looking over all above reference papers the majority of the work done identified with home mechanization. The proposed framework take couple of parameters identified with industry and give office identified with that .The proposed framework empowers us to screen and control machines from remote places just as gives data in regards to the support. This sort of framework helpful on the grounds that Human can commit errors and neglected to turn off the machine at explicit condition..

\section{REFERENCES}

1. E-Cleaning Waste Management System SidhantBansal, Rasveen

2. IoT Based Waste Management for Smart City Parkash, Prabu $\mathrm{V}$

3. IOT Based Waste Monitoring For Smart City Shambala S Salunkhe, Madhuri D Yadav,Vrushali V Kulkarni

4. Waste Bin Monitoring System Using Integrated Technologies KanchanMahajan, Prof.J.S.Chitode 